\title{
SISTEM PENGOLAHAN BAHAN PUSTAKA DI PERPUSTAKAAN SMPN 6 MATARAM
}

\author{
Lubis $^{1}$, Widyastuti Furbani ${ }^{2}$, Wisnu Dwicahyadi ${ }^{3}$ \\ Jurusan Ilmu Perpustakaan, Fakultas Ilmu Sosial dan Ilmu Politik \\ Universitas Muhammadiyah Mataram \\ lubis.vharoso@gmail.com
}

\section{INFO ARTIKEL}

Riwayat Artikel:

Diterima:...-...-...

Disetujui:...-...-...

\section{Kata Kunci:}

Pengolahan, bahan pustaka, perpustakaan sekolah

\begin{abstract}
ABSTRAK
Judul penelitian yang diambil adalah "sistem pengolahan bahan pustaka di perpustakaan SMPN 6 Mataram" tujuan dari penelitian ini diarahkan untuk mencapai hal-hal sebagai berikut : Tujuan penelitian yaitu (1) Untuk mengetahui sistem pengolahan bahan pustaka di perpustakaan SMPN 6 Mataram dan.

Jenis penelitian ini adalah penelitian deskriptif dengan pendekatan kualitatif. Sumber data dalam penelitian ini adalah pengelola perpustakaan SMPN 6 Mataram. Teknik pengumpulan data melalui observasi, wawancara dan dokumentasi. Teknik analisis data dalam bentuk reduksi data, penyajian data dan menarik kesimpulan untuk memperoleh hasil akhir.

Dari data hasil penelitian dan pembahasan diketahui bahwa (1) sistem pengolahan bahan pustaka di perpustakaan SMPN 6 Mataram dilakukan pengecekan bahan pustaka, inventarisasi, katalogisasi, penentuan nomor klasifikasi, pelabelan dan penataan buku di rak (shelving).
\end{abstract}

Abstract:

The title of the study was "library material processing system in the library of SMPN 6 Mataram". The purpose of this study was directed to achieve the following: The research objectives are (1) To find out the library material processing system at the library of SMPN 6 Mataram and.

This type of research is a descriptive study with a qualitative approach. The data source in this study is the manager of the Mataram 6 Public Middle School library. Data collection techniques through observation, interviews and documentation. Data analysis techniques in the form of data reduction, data presentation and drawing conclusions to obtain the final results.

From the research and discussion data it is known that (1) library material processing system in the library of SMPN 6 Mataram checking library materials, inventorying, cataloging, determining classification numbers, labeling and structuring books on shelving.

\section{A. LATAR BELAKANG}

Dalam upaya mencerdaskan kehidupan bangsa, maka perpustakaan dapat digunakan sebagai tempat mengumpulkan, mengolah, menyimpan dan memelihara koleksi bahan pustaka yang dikelola dan diatur secara otomatis dengan cara tertentu, untuk digunakan secara baik oleh pemakainya sebagai sumber informasi. Perpustakaan sekolah adalah suatu ruangan bagian dari gedung atau bangunan tersendiri yang berisikan buku-buku koleksi yang disusun dan diatur sedemikian rupa sehingga mudah untuk dicari dan dipergunakan apabila sewaktu waktu diperlukan oleh pembaca. Jadi, Perpustakaan merupakan suatu tempat yang digunakan dan disediakan oleh sekolah untuk warga sekolah yang ingin membaca atau meminjam koleksi buku-buku perpustakaan. Oleh karena itu perpustakaan sekolah mutlak dibutuhkan oleh siswa, sebab di dalam perpustakaan itulah mereka memperoleh banyak ilmu pengetahuan dan informasi. Adanya informasi yang pesat dan membawa banyak perubahan pada semua sektor kehidupan dan telah mengantarkan kita ke arah kemajuan yang lebih modern (Bafadal, 2011).

Sebuah perpustakaan agar dapat dikelola dengan baik maka harus memenuhi persyaratan yang akan dilakukan menurut standar pengolahan perpustakaan, semua sumber informasi yang dimiliki di manfaatkan 
oleh pemakainya secara optimal dan dapat memberikan nilai tambah bagi penggunaanya. Pengolahan informasi di perpustakaan akan lebih berdaya guna dan berhasil guna apabila dikelola oleh seseorang ahli perpustakaan yang memiliki ilmu pengetahuan dibidang perpustakaan, agar perpustakaan berperan sesuai fungsi dan tujuannya maka para pengelola perpustakaan harus sadar akan arti dan kedudukan perpustakaan bagi pengguna, memahami kebutuhan dan selera pembacanya, memahami kegatan perpustakaan serta mampu secara teknis dalam melakukan pengolahan perpustakaan. Kegiatan pengolahan perpustakaan adalah salah satu aset penting yang harus diperhatikan dalam pengolahan suatu perpustakaan karena tolak ukur dari keberhasilan suatu perpustakaan dapat dilihat dari segi pengolahan baik perpustakaan. Dikalangan pustakawan istilah pengolahan dapat diterjemahkan menjadi bagian penafsiran diantaranya, pengolahan atau processing koleksi perpustakaan merupakan serangkaian pekerjaan dilakukan sejak bahan pustaka diterima oleh perpustakaan sebagai dengan siap dipergunakan oleh pemakai, tujuanya agar semua koleksi dapat ditemukan atau ditelusur dan dipergunakan denan mudah oleh pemakai. (Sutarno, 2005).

Dari pernyataan di atas maka dapat disimpulkan bahwa pengolahan bahan pustaka adalah salah satu kegiatan yang dilakukan secara sistematis mulai dari bahan pustaka tersebut masuk hingga siap untuk digunakan oleh pengguna (user), yang bertujuan memberikan kemudahan penelusuran informasi bahan pustaka. Sebagaimana dalam Undang-Undang No.43 Tahun 2007 tentang perpustakaan pasal 11 ayat 2 yang menyatakan bahwa standar nasional perpustakaan sebagaimana yang dimaksud pada ayat 1 (standar pengelolaan) digunakan sebagai acuan penyelenggaraan, pengelolaan, dan pengembangan perpustakaan. Perkembangan ilmu pengetahuan yang begitu pesat membuat pihak perpustakaan harus meningkatkan dan menambah koleksi bahan pustaka baik yang tercetak maupun yang tidak tercetak. Setiap koleksi bahan pustaka yang diterima suatu perpustakaan baik yang berasal dari pembelian, hadiah atau sumbangan, baik tukar menukar maupun terbitan sendiri belum dapat ditempatkan di dalam rak dan dipinjamkan kepada pengguna sebelum di adakannya suatu pengolahan (kemenkumham, 2009).

Dari pernyataan tersebut maka perpustakaan harus dapat menyediakan bahan pustaka yang dibutuhkan oleh pengguna harus teredia meskipun tidak semuanya harus ada diperpustakaan. Hal ini disebabkan karena tidak ada perpustakaan yang memiliki semua koleksi yang ada. Oleh karena itu perpustakaan dijadikan sebagai suatu tempat mengumpulkan, mengolah, menyimpan, dan memelihara koleksi bahan pustaka yang dikelola dan diatur secara otomatis dengan cara tertentu, untuk digunakan secara baik oleh pemakainya sebagai sumber informasi dan dapat dengan mudah memanfaatkan informasi yang dibutuhkan.

Berkenan dengan hal itu penulis mengkaji lebih dalam mengenai bagaimana pengolahan bahan pustaka di perpustakaan sekolah dan menuangkannya dalam laporan yang berjudul: Sistem Pengolahan Bahan Pustaka di Perpustakaan SMPN 6 Mataram. penulis memilih pokok pembahasan ini dikarenakan pengolahan bahan pustaka merupakan kegiatan pokok disuatu perpustakaan sekolah dalam mempermudah penelusuran informasi.

\section{B. METODE PENELITIAN}

Jenis penelitian ini adalah penelitian deskriptif dengan pendekatan kualitatif. Sumber data dalam penelitian ini adalah pengelola perpustakaan SMPN 6 Mataram. Teknik pengumpulan data melalui observasi, wawancara dan dokumentasi. Teknik analisis data dalam bentuk reduksi data, penyajian data dan menarik kesimpulan untuk memperoleh hasil akhir. 


\section{HASIL DAN PEMBAHASAN}

Berdasarkan analisis sistem pengolahan bahan pustaka di perpustakaan SMPN 6 Mataram, maka penulis menginterpretasikan hasil analisis penelitian ini dalam pembahasan berikut ini.

\section{Sistem Pengolahan Bahan Pustaka Di Perpustakaan SMPN 6 Mataram}

Di perpustakaan SMPN 6 Mataram di dalam pengolahan bahan pustaka masih tergolong manual maka perlu ada perhatian dalam melakukan kegiatan pengolahan bahan pustaka agar dapat mempermudah penelusuran informasi dan dimanfaatkan oleh pemustaka kegiatan yang dilakukan adalah sebagai berikut :

\section{Inventarisasi}

Inventarisasi adalah pencatatan setiap eksamplar bahan pustaka di buku induk. Kegiatan inventaris masih menggunakan sistem manual karena memang pustakawan belum pernah menggunakan inventarisasi yang ada di SLIMS dan juga ada beberapa kegiatan yang belum bisa dilakukan oleh komputer. Adapun proses inventarisa sisecara manual yaitu seperti:

a. Sebelum melakukan pencatatan bahan pustaka dibuku induk terlebih dulu kita memberikan stempel pada buku. Stempel dilakukan secara manual oleh Pustakawan. Stempel buku diberikakan pada bagian-bagian tertentu seperti: dibalik halaman judul, halaman tengah isi buku dan halaman belakang buku. Stempel berfungsi sebagai identitas kepemilikan buku sehingga apabila buku tersebut hilang dan ditemukan seseorang maka dengan mudah untuk dikembalikan ke perpustakaan.

b. Pencatatan bahan pustaka di buku induk, pencatatan dilakukan agar bahan pustaka yang sudah dibeli memang itulah bahan pustaka yang diterima. Pencacatan nomner inventarisasi buku dimulai dari nomer 1, 2, 3 atau bisa juga dimulai dari 01, 02, 03 dan seterusnya. Nomer inventarisasi ini berganti setiap tahun. Dengan sistem bahan pustaka yang dimiliki perpustakaan setiap tahunya dapat diketahui jumlahnya.

Dalam aplikasi Senayan Library Managemen Sistem (SLIMS) inventarisasi (Stock Opname) bahan pustaka yang berfungsi untuk mengtahui informasi jumlah dan judul koleksi yang masih tersedia, hilang dan yang sedang dipinjam oleh pengguna dengan cepat dan akurat. Menu ini berisikan seperti gambar 1 dibawah ini : .

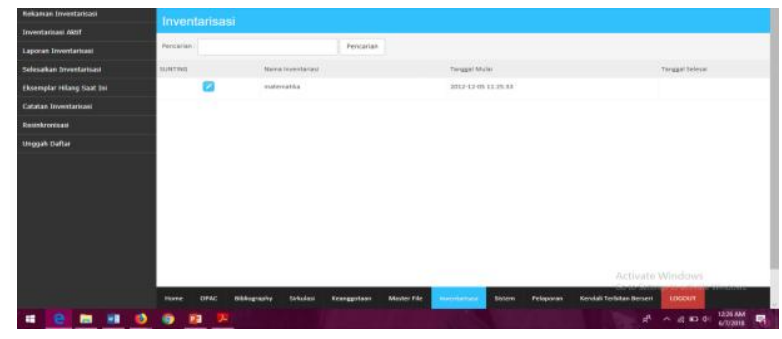

\section{Klasifikasi (Dewey Decimal}

\section{Classification)}

Klasifikasi bahan pustaka adalah pengolongan berdasarkan subjek atau isi bahan pustaka. Selanjutnya adalah kegiatan menganalisis bahan pustaka dan menentukan notasi yang mewakili subjek bahan pustaka dengan menggunakan sistem klasifikasi Dewey Decintal Classification (DDC) yang terbagi menjadi 10 kelas utama.

\section{Katalogisasi}

Katalog merupakan daftar susunan alfabetis tentang suatu barang, item atau bahan lain dengan tambahan informasi singkat dari bahan atau item tersebut termasuk ukuran, warna bahkan harga. Tujuan dari pembuatan katalog adalah agar mempermudah pemustaka maupun petugas perpustakaan di dalam penelusuran informasi.

Proses kegiatan pengkatalogan di perpustakaan SMPN 6 Mataram belum pernah melakukan kegiatan pengkatalogan sebagaimana mestinya kegiatan membuat dekskripsi data bibliografi suatu bahan pustaka menurut standar 
atau peraturan tertentu, maka pembuatan katalog sangat penting di dalam suatu perpustakaan agar dapat mempermudah pencarian informasi.

Katalog adalah daftar pustaka (buku) yang dimiliki perpustakaan yang tersusun secara sistematis sehingga dapat diugunakan untuk mencari dan menemukan lokasi pustaka dengan mudah dan cepat.

\section{KESIMPULAN DAN SARAN}

\section{Kesimpulan}

Berdasarkan hasil penelitian, maka dapat diambil kesimpulan sebagai berikut :

a. Sistem pengolahan bahan pustaka di perpustakaan SMPN 6 Mataram meliputi kegiatan inventarisasi, klasifikasi, katalogisasi, penyusunan kartu katalog, dan sistem pelayanan perpustakaan sampai saat ini belum sepenuhnya dilakukan secara digital.

\section{Saran}

Berdasarkan kesimpulan diatas dan dalam rangka meningkatkan mutu pelayanan perpustakaan dan shelving (penyusunan buku di rak) di Perpustakaan SMPN 6 Mataram. Maka penulis menyampaikan saran-saran sebagai berikut: a. Perpustakaan SMPN 6 Mataram perlu meningkatkan pengetahuan dan profeisonal tenaga pustakawan sehingga dalam memberikan pengolahan bahan pustaka tidak ada lagi hambatan yang terjadi.

\section{DAFTAR RUJUKAN}

Bafadal ,Ibrahim. Pengelolaan perpustakaan sekolah.cetakan ke 2 . Jakarta: bumi aksara 1996 Bagong Suyanto, Sutina. Penelitian Kualitatif. Jakarta, 2005

Nasir.Jenis penelitian deskriptif kualitatif. Jakarta: 2005.

Pawit, M. Yusuf. Pedoman penyelenggaraan perpustakaan sekolah 2005.

Rosalin .Pemamfaatan perpustakaan dan sumber informasi .bandung: PT mandiri persada 2008

Sinaga, Dian. Mengelola perpustakaan sekolah bandung : kiblat buku utama, 2004

Soetimah.Perpustakaan kepustakawanan dan pustakawan .yoigyakarta: kanisius, 1992

Sulistiyo-Basuki.Pengantar Ilmu Perpustakaan. Jakarta: Gramedia Pustaka Utama,1993.

Sutarno NS .Menejemen perpustakaan.Jakarta : samitra media utama, 2004. 